\title{
A Methodology of Energy Optimization in Indoor Swimming Pool
}

\author{
Alessia Natali ${ }^{1 *}$, Michele Bottarelli ${ }^{1}$, Patrizio Fausti $^{2}$ \\ ${ }^{1}$ Department of Architecture, University of Ferrara, V. Quartieri 8 - 444121, Ferrara, Italy \\ ${ }^{2}$ Department of Engineering, University of Ferrara, V. Saragat 1 - 444124, Ferrara, Italy
}

Corresponding Author Email: alessia.natali@unife.it

https://doi.org/10.18280/ti-ijes.642-402

Received: 3 February 2020

Accepted: 23 May 2020

\section{Keywords: \\ swimming pool, energy savings, TRNSYS, \\ dynamic analysis, energy efficiency}

\begin{abstract}
Swimming pools require a large amount of energy to provide comfort for the swimmers, therefore, energy saving actions must be studied in order to optimise their efficiency even when the existing systems are already of high performance. The case study relies on a public indoor swimming pool, in which dynamic simulations were developed by using TRNSYS software. Experimental measurement campaign was also performed in order to investigate the system operation to calibrate the numerical model by using the real data. Starting from the virtual model of the pool centre different energy efficiency actions have been analysed in the interest of find achievable energy savings. The first action is related to a new management of the pool centre and involves the reduction of evaporation losses from the water pool surface; the other action proposes to increase the heating supply coming from renewable source. The results of the analysis outline that both proposed solutions permit a reduction of total heat needs and therefore of the amount of primary energy. This permits to carry out replicable analyses by adapting the studied plant system to different operating swimming centres systems, investigating their efficiencies and identifying solutions for energy saving actions.
\end{abstract}

\section{INTRODUCTION}

Swimming pools for sports and entertainment are high energy-consuming structures. The large amount of energy that they require is necessary to provide comfort for the swimmers and to make up for the dispersion through the building envelope. For indoor swimming pools, several environmental parameters should be checked, such as the temperature of the air and pool water and the humidity, determined by the considerable rate of water evaporation from the pools, bathers and showers.

Since there is a constant energy requirement from the pool, the most frequently used technologies in pool heating are water heaters that use fossil fuels such as diesel and natural gas. The burning of such fuels generates greenhouse emissions, which affect climate change [1]. Furthermore, the cost of fossil fuels has increased considerably in the last years. These factors shown the importance of investigating possible ways of using renewable energy technologies which combine the requirement of reducing costs and $\mathrm{CO}_{2}$ emissions into the atmosphere [2], achieving the objectives proposed by the European Union for a more efficient energy use. Several projects have been funded by the EU dealing with energy efficiency and the use of renewable energy sources in sport centres $[3,4]$. Jordaan et al. developed a model to study the various heating options with the aim of investigating the reduction of natural gas when applying alternative heating concepts that exploit renewable energy or higher coefficients of performance [5]. Delgado implemented a predictive control system in order to reduce a swimming pool's energy demand using less fuel [6]. Artuso and Santiangeli [7] developed a tool for the preliminary estimation of sports centres' energy demand. The integration of renewable energy sources has been taken into account in order to analyse the possibility of a selfsufficient building from the energy point of view. The analysis outlined that a $100 \%$ renewable energy system is possible, with a reduction of $6000 \mathrm{t} /$ year of $\mathrm{CO}_{2}$ emissions compared to a traditional system.

Many sports facilities have already been improved in terms of their efficiency, with actions that include the installation of solar panels for the use of renewable sources, the simultaneous production of electricity and useful heat with cogeneration plants, the installation of condensing boilers or led lighting. Different renewable energy sources can be exploited in order to match the energy demands of a sport centre, such as: solar [8], biomass [9], geothermal [10] and their combination.

Nowadays, particular attention is given by the recent literature to sport centres which include a swimming pool. Buonomano et al. [11] studied the technical feasibility and energy performance of a PhotoVoltaic/Thermal (PVT) collector system for an indoor/outdoor swimming pool, under the Mediterranean climatic conditions in order to find the optimal PVT collector field area. Another study by Chow et al. [12] analyses a Solar Assisted Heat Pump (SAHP) system for indoor swimming pool heating purposes during winter period operation. The results demonstrate that the system can achieve a high COP and higher energy saving compared to the conventional energy system. Katsaprakakis [13] studied different passive and active heating systems for swimming pools. For the passive heating, systems such as the pool's envelope and a floating insulating cover were considered, while a biomass heater and a vertical geothermal heat exchanger (GHE) co-operating with geothermal heat pumps (GHP) were considered as active systems. 
Thermal solar panels coupled with heat pumps are nowadays very promising systems for water and air heating. A system including a Water Solar Assisted Heat Pump (WSAHP) coupled with unglazed flat plate collectors was considered for a swimming pool installation by Tagliafico et al. [14]. The study was carried out in order to find a correlation between heating degree days and primary energy saving index. Another study dealing with heat pumps was developed by Sun et al. [15], where the authors investigated a new heat pump dehumidifier to reduce energy consumption in an indoor pool. Calise et al. [16] investigated the possibility to perform an energy rehabilitation of an indoor swimming pool centre by means of solar and heat pump technologies, integrated in the existing conventional thermal installation. An air-to-water heat pump and several types of thermal collector, such as unglazed, glassed, non-selective, selective and evacuated, have been considered in order to be coupled with the heat pump.

The available literature shows an increasing, though still limited, number of papers dealing with energy saving issues relating to sport centres which include a swimming pool installation. Despite possible measures concerning energy efficiency or renewable energy adopted in the plant systems, there is still a high potential for energy saving actions. Thus, the investigation described in this article attempted to identify the capacity of various heating applications to save energy whilst maintaining the heating demands of the pool: the first application is related to the reduction of the evaporation losses, the second solution proposes recovering heat from expelled water. This study was possible by developing a pool model with different heating configurations, where each heating option was assessed by means of a transient simulation. The comparison allowed each heating configuration to be evaluated in terms of energy saving and heating potential. The proposed comparison represents a novelty in the sector as few analyses of this type have been carried out so far.

\section{CASE STUDY}

The pool analyzed in this study is the Piscina Beethoven located in Ferrara, Italy, which is the main public plant of the city. The pool envelope was built in the 80 s, while the swimming pool's system was redesigned in 2013 following renovation of the centre that led to its extension. A fitness pool and an outdoor pool were annexed to the swimming centre. Therefore, currently the sports centre is characterised by four different pools, three of which are indoor and one outdoor, used only during the summer. The indoor pools are used for different aims like competitions, swimming lessons and fitness; consequently, they have different dimensions and depths.

\subsection{System description}

Heat production is provided by an integrated system consisting of: two condensing boilers powered by natural gas, a micro-cogenerator for the combined production of electricity and heat, solar thermal collectors for the production of DHW and an air-to-water HP. The HP provides the DHW preheating during winter time and the room conditioning during summer time. The user side, instead, is represented by: the request of DHW, the radiator circuit, the fan-coil circuit and the AHU circuit.

DHW is firstly heated in a tank with 2000 litres capacity through an integrated system consisting of a HP and solar thermal collectors. Subsequently the water is sent into a postheating tank and in order to raise its temperature the tank is coupled with an external heat exchanger connected to the boilers circuit. The average temperature of the preheating tank is around $20-25^{\circ} \mathrm{C}$, while the water temperature of the postheating tank is higher: about $60^{\circ} \mathrm{C}$. The DHW delivery temperature is $42^{\circ} \mathrm{C}$. Since the focus of the manuscript is on the winter period, only the heating is discussed. The radiators control the changing rooms' heating, while the fan coils provide the regulation of the air temperature at the entrance to the swimming centre. The AHU circuit deals with the treatment of air in the pool room and in the locker room, and with the pool's hot water production. More in detail, the air treatment is realised by means of a centrally located packaged rooftop air handler, which contains a variable speed fan, an electric resistance preheat coil and a direct expansion cooling coil. Figure 1 depicts the global pool plant.

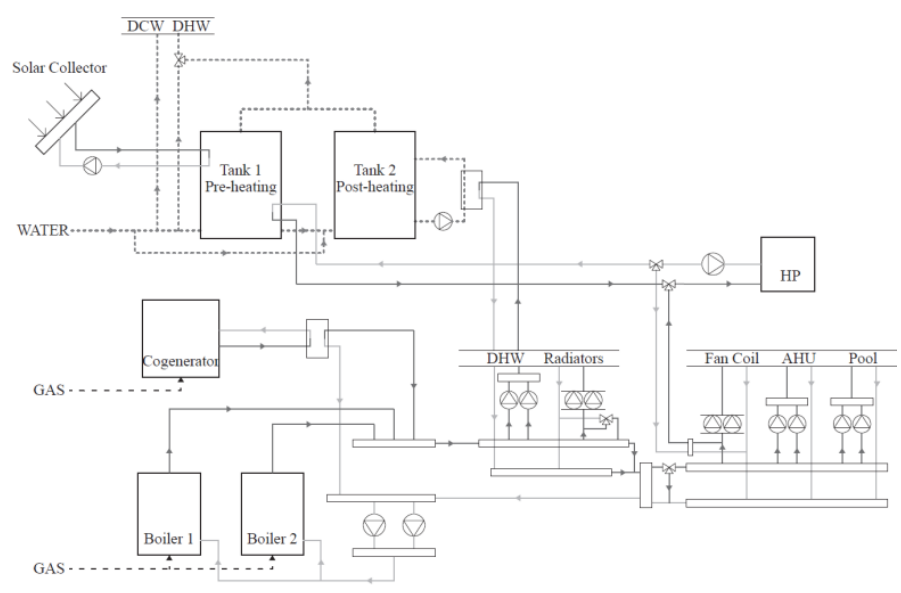

Figure 1. Pool system

\section{METHODOLOGY}

The study was carried out using TRNSYS software, a graphically based software environment used to simulate the behaviour of transient systems and to assess the performance of thermal and electrical energy systems in their entirety.

TRNSYS already includes in its library some components based on algebraic equations, each of which models the performance of one part of a system. The validity of these equations has been cross-checked with ASHRAE standards [17]. Other components are based on a data lookup approach where the performance is based on manufacturer data, therefore such components are intrinsically validated. The use of a dynamic simulation permits to study the global system in the real operative conditions, solving the global transient equations at every time step, and giving more accurate results.

\subsection{Model development}

The building was modelled as a multi-thermal-zone building using the standard TRNBuild type. In this module all the building structure details were specified, as well as the envelope properties, heating and cooling schedules.

The cogeneration system was modelled using Type907, Type5g and Type9: they represent respectively the engine motor, the fume recuperator and the heat exchanger. The fume recuperator allows an energy transfer from the exhaust steam 
stream to the engine working fluid, while the plate exchanger provides the heat exchange from the recovered heat to the working fluid of the hydronic system. For the boilers Type 700 was chosen. For DHW production, the following types were chosen: Type534 for the tanks, Type1a for the solar collector, Type941 for the air to water HP. Type1231 was used in order to model low-temperature hydronic heat-distributing units such as radiators. These types of unit supply heat through a combination of radiation and convection without fans. The fan coil units were provided by the coupling of a hydronic hot water coil, Type140, linked to the central boiler circuit, and a fan, modelled by Type164. The fan was assumed to be at constant speed and to run intermittently as required by the thermostat to maintain a heating set point during the building's unoccupied hours. The thermostat corresponds to Type166. The type selected for the simulation of the swimming pool's AHU was Type151. The assessment of the indoor swimming pool was based on Type 344, a nonstandard Type provided by TRANSSOLAR.

\subsubsection{Pool TRNSYS model}

The mathematical model for the pool comprises a balance of energy gains and losses, according to Eq. (1).

$$
V_{p} \rho_{w} C_{p, w} \frac{d T_{p}}{d t}=\frac{Q_{\text {gain }}}{d t}-\frac{Q_{\text {losses }}}{d t}
$$

The heat gains and losses are due to the heat exchange with the surroundings and include: the heat flow rate by evaporation $Q_{\text {evap }}$, the heat flow rate by convection $Q_{c o n v}$, the heat flow rate by long-wave radiation $Q_{\text {rad }}$, the heat loss by fresh water supply $Q_{\text {refill }}$, the heat flow rate from heating $Q_{i n}$, and the thermal conduction to the ground $Q_{\text {cond }}$. The heat flow rate to the ground is negligible for this assessment. The other heat flow rates are calculated in detail using the equation available in the technical literature [18-23].

The heat loss by evaporation can be calculated on the basis of the evaporated mass flow rate with the following expression, Eq. (2):

$$
Q_{\text {evap }}=\dot{m}_{\text {evap }} \Delta h_{\text {evap }}
$$

For an indoor pool, the evaporated mass flow rate can be calculated from the equation Eq. (3):

$$
\dot{m}_{\text {evap }}=w A_{\text {tot }}\left(p_{\text {sat }}\left(\theta_{p}\right)-p_{\text {st }}\left(\theta_{\text {amb }}\right)\right)
$$

The total evaporation coefficient $w$ is taken from the VD Guideline 2089 [24]. The steam pressure in ambient conditions can be calculated using the relative humidity determined by the formula presented in Eq. (4):

$$
p_{s t}=\varphi_{a m b} p_{s a t}\left(\theta_{a m b}\right)
$$

The heat flow rate by convection can be calculated using the Newton's formula:

$$
Q_{\text {conv }}=h^{*} A_{\text {tot }}\left(\theta_{p}-\theta_{a m b}\right)
$$

The heat transfer coefficient can be calculated on the basis of the total evaporation rate, as found by Czarnecki [25].

The heat transfer rate by long-wave radiation exchange with the walls can be calculated on the basis of the Stefan-
Boltzmann law, Eq. (6):

$$
Q_{\text {rad }}=A_{\text {tot }} \varepsilon_{w} \sigma\left(T_{p}^{4}-T_{w a l l}^{4}\right)
$$

where, $\varepsilon_{w}=0.9$.

The heat loss by fresh water supply can be calculated using the first law of thermodynamics under the assumption of an incompressible liquid as follows, Eq. (7):

$$
Q_{\text {refill }}=m_{\text {refill }} C_{p, w}\left(\theta_{p}-\theta_{\text {refill }}\right)
$$

Analogous to the heat loss by fresh water supply, the heat flow rate of the auxiliary heating can be calculated from the formula expressed in Eq. (8):

$$
Q_{\text {in }}=m_{\text {in }} C_{p, w}\left(\theta_{p}-\theta_{\text {in }}\right)
$$

\subsection{Model calibration}

During the geometrical modelling, the building was simplified and divided into five thermal zones: the pool room, the changing room, the warehouse, the unheated room and the hall/bar area. The zones were grouped by similar thermohygrometric characteristics. A graphical representation of this division is depicted in Figure 2.

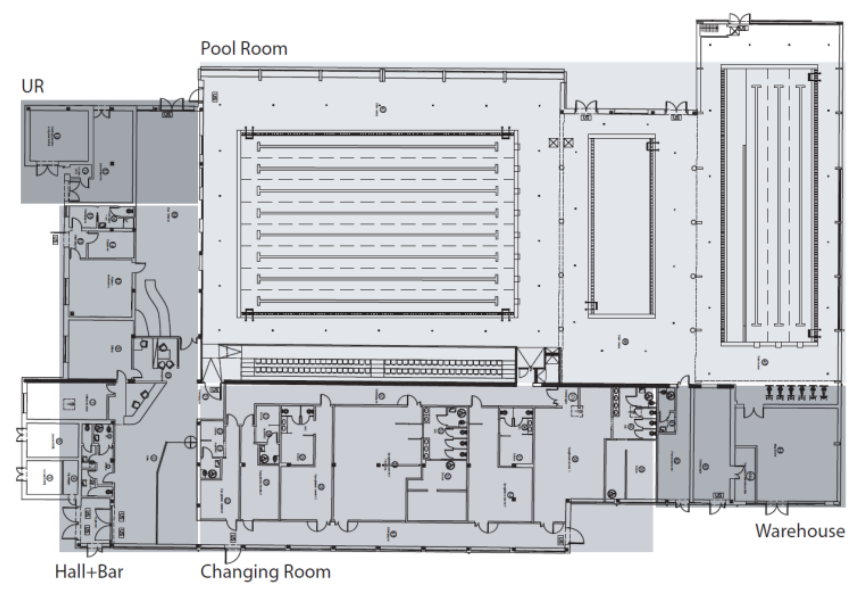

Figure 2. Swimming centre thermal zone

For what concern the swimming pool area, the centre is composed of three different pools, but with the purpose of reducing the complexity of the TRNSYS model, it was implemented by using a single pool characterised by average values in terms of water temperature and depth. Table 1 describes the pools' characteristics, and the characteristics of the modelled one.

Table 1. Pool characteristic

\begin{tabular}{cccc}
\hline $\begin{array}{c}\text { Pool } \\
\text { dimension }\end{array}$ & $\begin{array}{c}\text { Depth } \\
{[\mathbf{m}]}\end{array}$ & $\begin{array}{c}\text { Surface } \\
{\left[\mathbf{m}^{\mathbf{2}}\right]}\end{array}$ & $\begin{array}{c}\text { T water pool } \\
{\left[{ }^{\circ} \mathbf{C}\right]}\end{array}$ \\
\hline Big & 1.60 & 400 & 28.5 \\
Medium & 1.30 & 190 & 30 \\
Small & 0.60 & 80 & 31 \\
\hline Modelled pool & 1.47 & 670 & 29 \\
\hline
\end{tabular}

In order to calibrate the model, it was also necessary to acquire information on the temperature and working fluid mass flow rate. The pool plant is already equipped with a PLC which allows the monitoring of working fluid temperature, but 
during the data processing it was found that the thermocouples coupled with the PLC were inaccurate and numerically insufficient to describe the entire system. Owing to the lack of information, an experimental measurement campaign was performed in order to investigate the existing system installation operation. To carry out the measurements some thermocouples and a data logger for signal recording were used. The data logger was ALMEMO 710 produced by Ahlborn. For what concern the mass flow rate, it is worth noting that it was not directly acquired during the experimental activity since the system is not equipped with flowmeters. Therefore, mass flow rates were read in correspondence to the circulation pumps' display, even if this value is affected by a high degree of uncertainty.

Furthermore, air temperature of the five thermal zones, DHW and pool water temperature were registered in order to set the initial conditions and calibrate the model. Such temperatures were set as Table 2(a) so the control system can manage the swimming pool heating system in order to achieve stably this temperature. The same process was carried out with the power consumption of the system components, see Table 2(b).

Table 2. (a) Air and water temperature, (b) System components power

\begin{tabular}{cccc}
\hline & Description & Zone/Element & Value and Unit \\
\hline \multirow{4}{*}{ (a) } & \multirow{3}{*}{ Air Temperature } & Pool room & $30^{\circ} \mathrm{C}$ \\
& & Changing room & $26^{\circ} \mathrm{C}$ \\
& & Hall+Bar & $20^{\circ} \mathrm{C}$ \\
& \multirow{3}{*}{ Water Temperature } & DHW & $42^{\circ} \mathrm{C}$ \\
& Pool & $29^{\circ} \mathrm{C}$ \\
\hline \multirow{4}{*}{ Power } & Boiler & $540 \mathrm{~kW}$ \\
& & Cogenerator & $80 \mathrm{~kW}$ \\
& & HX DHW & $150 \mathrm{~kW}$ \\
(b) & Radiators & $10 \mathrm{~kW}$ \\
& & Fan-Coil & $10 \mathrm{~kW}$ \\
& & AHU & $90 \mathrm{~kW}$ \\
& & Pool & $620 \mathrm{~kW}$ \\
& & HP & $40 \mathrm{~kW}$ \\
\hline
\end{tabular}

The objective of the simulation was to represent the real behaviour of the plant. Although the simulation of the pool system was carried out in the winter period, for the graphical output a shorter simulation time was chosen in order to give a better visualization of the results.

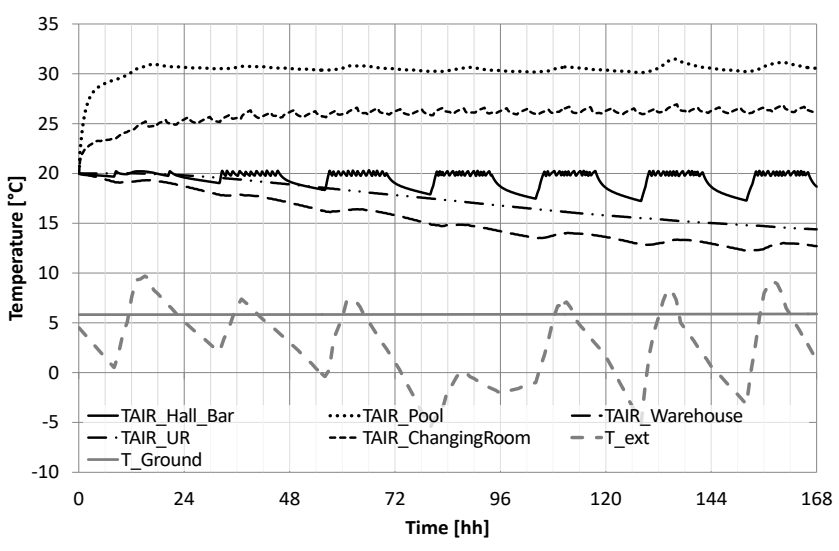

Figure 3. Thermal zones air temperature, outdoor and ground temperature

Focusing on the temperature of the three heated rooms, the entrance area with bar, the changing room and the pool room respectively, it can be concluded that the simulation outputs are consistent with the required comfort conditions. According to the standards, it is worth noting that the air temperature in the pool room does not exceed by more than approximately 1 $2{ }^{\circ} \mathrm{C}$ the temperature of the pool water contained. This prediction is completely respected because of the work of the AHU: the air temperature in this area remains around $30^{\circ} \mathrm{C}$. In the changing room a temperature around $26^{\circ} \mathrm{C}$ is maintained. Whenever the air temperature drops below the desired temperature, the radiators will be activated to restore the ideal thermal conditions. The fan coils, for which the night switchoff is provided, control the heating and cooling of the entrance and the bar area: the temperatures fluctuate around $20^{\circ} \mathrm{C}$ during the opening hours of the pool, while they drop during the closing hours when, in fact, the fan coils are in the off mode. It can also be seen that the warehouse and the technical room start the simulation with an initial temperature of $20^{\circ} \mathrm{C}$, but then their temperature decreases over time as they are not supplied with a heating system.

\subsection{Model validation}

Knowing the rated efficiencies of thermal machines, it is possible to know the correspondence between primary energy consumption and thermal efficiency of each machine. The rated efficiencies and the consumption of the condensing boiler, the cogenerator and the HP are indicated in Table 3.

Figure 4. Efficiency, primary energy consumption and thermal output of each thermal machine

\begin{tabular}{cccc}
\hline & Efficiency & $\mathbf{k W h} \mathbf{h}_{\text {therm }}$ of fuel & $\mathbf{k W h}_{\text {therm }}$ \\
\hline $\begin{array}{c}\text { Condensing } \\
\text { boiler }\end{array}$ & $106.5 \%$ & 1 & 1.065 \\
Cogenerator & $\begin{array}{c}\eta_{\text {cogen }}=82 \% \\
\text { (thermal: } 52 \%, \\
\text { electical: } 30 \%) \\
\text { COP }\end{array}$ & 1 & \\
HP & Total & 2.4 & 1.42 \\
& & 2 & 2.485 \\
\hline
\end{tabular}

Table 3 shows that, to obtain a thermal power equal to 2.485 $\mathrm{kWht}$ the system uses $2 \mathrm{kWht}$ of gas. Therefore, the factor related to this conversion is equal to 0.805 . With this value, it is possible to determine the transformation from [kWh] of natural gas to thermal $[\mathrm{kWh}$, and consequently it is possible to compare the natural gas consumption profile obtained by reading the pool's bills with the consumption profile obtained by the dynamic simulation performed with TRNSYS. Comparing the monitored daily consumption, which achieves the value of $9.8 \mathrm{MWht} / \mathrm{day}$, with the consumption resulting from the numerical simulation, equal to $8.1 \mathrm{MWht} / \mathrm{day}$, a difference of $17.3 \%$ is noticed between the two models. Although the gap between the two models is numerically not negligible, it was decided to accept it anyway, in light of the approximations made during the calibration of the virtual model due to the lack of information on the plant parameters.

\subsubsection{Model validation by evaporated mass flow rate:}

In order to determine analytically the quantity of water that evaporates from the surface, and therefore gives rise to evaporative dispersions, the empirical relation presented in Eq. (3), is used. The total evaporation coefficient $w$ for a choppy water surface is taken from the VD Guideline 2089 [24], and 
it is calculated as $w=\frac{k}{1000}$. Where $k$ is equal to 20 for public pools, and is equal to 28 recreational pools. For the calculation, in light of the approximations made on the pool's usage, surface and depth, an average value of $k=0.24$ is taken. The value of the total water surface $A_{\text {tot }}\left[\mathrm{m}^{2}\right]$ is assumed with reference to the Table 1 . The last term of the formula indicates the difference between the saturation pressure of the water steam at the water surface temperature and the zone conditions $[\mathrm{hPa}]$.

According to the analytic formula of the Eq. (3), the evaporated mass flow rate is equal to $260 \mathrm{~kg} / \mathrm{h}$. The results of the analysis made with TRNSYS indicate that the amount of evaporated water from the surface of the pool is around 268.5 $\mathrm{kg} / \mathrm{h}$. The difference between the analytic and the experimental results is equivalent to $3 \%$. Therefore, the results are consistent, which means that the pool model represents the real case with a good approximation.

\section{RESULTS}

\subsection{Energy efficiency actions}

In order to achieve energy saving, some energy efficiency actions are possible for swimming pools. This article analyses two of them: the first solution is related to the reduction of losses from the water pool surface, the second proposes an increasing energy supply coming from a renewable source.

\subsubsection{Reduction of evaporation rate}

The use of a thermal swimming pool cover during non-use hours, so during night time, can reduce heat loss and the amount of water needed for the daily replacement by reducing water evaporation. The reduction of the moisture on the building structure produces two different advantages. The first is related to the healthiness and time life of the structure itself; the second advantage is that it would allow the ventilation system to work at partial load or even to be switched off during periods of closure to the public. This would permit an important reduction in the AHU's thermal and electrical consumption, with considerable energy savings. The adoption of thermal pool covers does not require special installation conditions; they can be easily installed in all swimming centres and have a relatively low investment cost and amortization time [26].

\subsubsection{Free energy from heat pump}

Swimming pools contain large masses of water that must be kept at a controlled temperature. Such amount of heat, necessary to heat up the water temperature till to the request value and then for its maintaining, can come from a renewable energy source by means of a combined use of a heat exchanger and water-to-water HP. This allows considerable energy savings.

The plant under study is already equipped with a HP, through which an integration of the DHW production is carried out during the winter period, guaranteeing total coverage from renewable sources. The HP preheats the first DHW storage tank, filled with the water coming from the water network, and keeps it at an average temperature of $20-25^{\circ} \mathrm{C}$. However, the users only request hot water during the pool opening hours, i.e. from 8:00 am to $10: 00 \mathrm{pm}$, so it can be deduced that the continuous operation of the thermal machine is not currently envisaged, and therefore remains off during the night. The proposed solution exploits the continuous operation of a water-to-water HP, in order to maintain the pools' water temperature during the night. Therefore, a modification of the HP circuit is foreseen: a divergent can be installed which, during daylight hours, will give priority to the DHW circuit, allowing the preheating of the water in the first storage tank. Instead, during night time, it will divert the working fluid towards the circuit that supplies the plate heat exchangers of the pools

\subsection{Analysis of results}

\subsubsection{Reduction of evaporation rate}

Type 344 allows the user to insert a cover sheet. Figures 4 and 5 report the output of the simulation referring to the ideal case in which the thermal conductivity of the isothermal cover is equal to zero $(\lambda=0 \mathrm{~W} /(\mathrm{mK}))$.

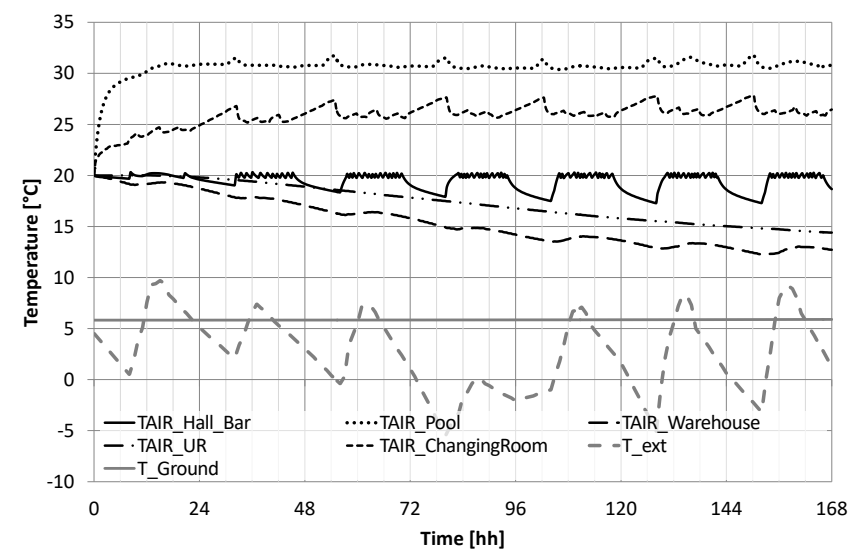

Figure 5. Thermal zones air temperature, outdoor and ground temperature

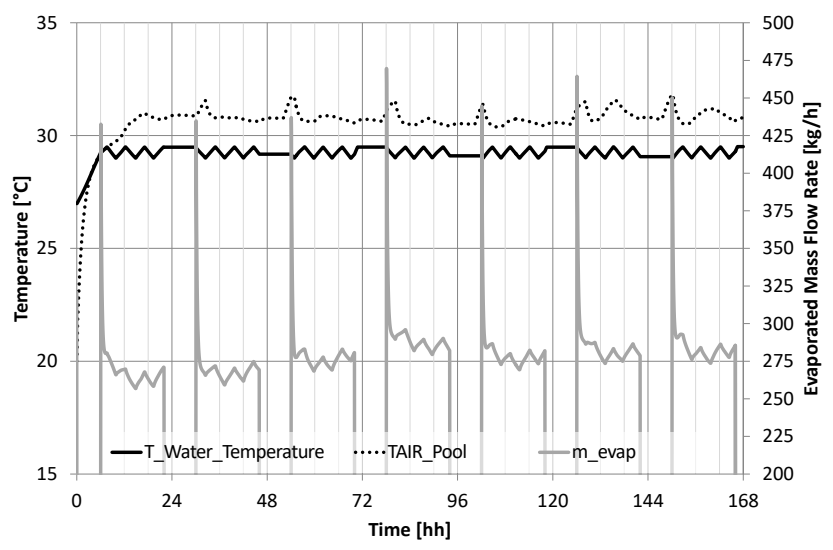

Figure 6. Pool water temperature and evaporated mass flow rate behavior

Figure 4 shows that the air temperature in the various rooms, except for a few moments, respects the desired comfort conditions. Some anomalies are found shortly before the turning on of the boilers, so before 8:00 am. This happens because the condensing boilers are not modulated and this create an anomaly in the numerical simulation. As in the first simulation, the air temperature in the hall/bar area is maintained at around $20^{\circ} \mathrm{C}$ during opening hours and drops when the fan coils are turned off. For the air temperature of the two unheated rooms there is, as in the simulation of the real 
case, a progressive decreasing of the temperature due to the absence of a heating system.

What varies significantly from the real case is the water flow rate evaporated from the pool surface, as represented in Figure 5. In this ideal solution, where the thermal conductivity of the covering is equal to $0 \mathrm{~W} /(\mathrm{m} . \mathrm{K})$, during night-time the evaporation of the pool water is completely avoided. The figure shows that during the hours in which the pool is covered by the isothermal sheet, the evaporation is zero, while it returns to oscillate around the value of $270 \mathrm{~kg} / \mathrm{h}$ during opening hours. Spreading the amount of evaporated mass flow rate over the simulation time, an hourly rate of $186.9 \mathrm{~kg} / \mathrm{h}$ is obtained. The anomalous peaks that are periodically found when the evaporative phenomenon starts, and which affect punctually the air temperature in the pool room, are related to the overheating of the working fluid due to the inability to modulate of the two boilers, as mentioned in the previous paragraph; in light of this the peaks are negligible. The air temperature in this thermal zone is always around $30{ }^{\circ} \mathrm{C}$ and it remains constant during the hours in which the pools are covered.

\subsubsection{Free energy from heat pump}

This solution proposes to exploit the 24-hour operation of a water-to-water heat pump as a renewable energy source. Therefore, a diversion of the hydronic circuit through the heat pump is planned by means of a divergent, Type 647, which assumes the role of a three-way valve with diverter function.

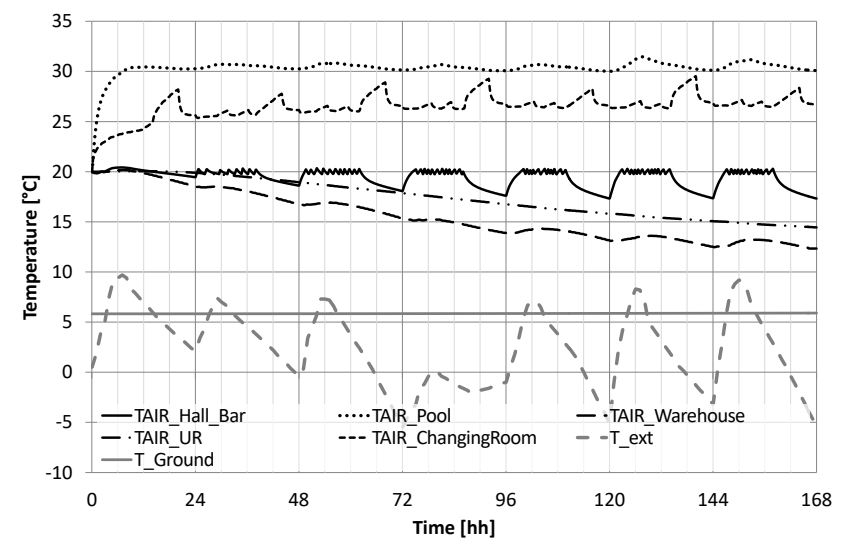

Figure 7. Thermal zones air temperature, outdoor and ground temperature

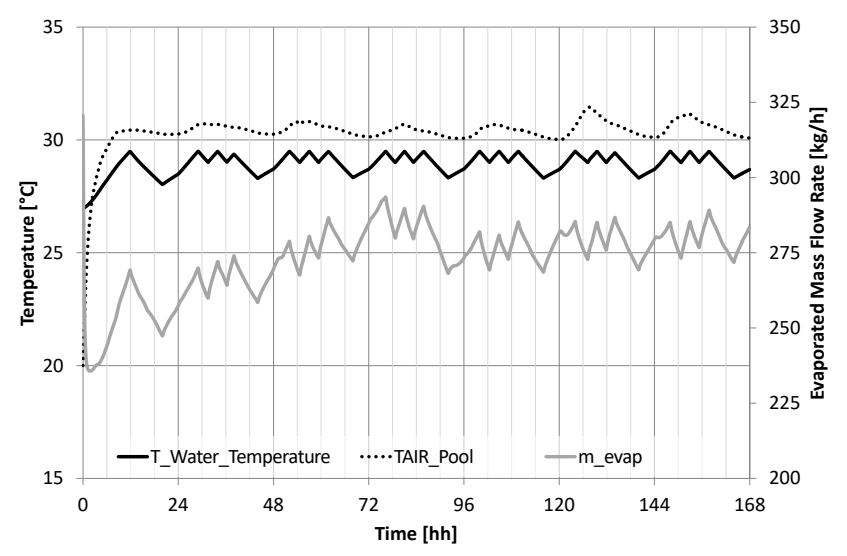

Figure 8. Pool water temperature and evaporated mass flow rate behavior
Also in this case the temperatures in the various thermal zones are maintained around the comfort conditions, even if some anomalies are found, as shown in Figure 6. The explanation behind these uncontrolled peaks is linked, as in the previous simulation, to the impossibility of the boiler modulation.

Different results are found for the air and water temperature in the pool room, since during the day the energy source used for the heating changes, see Figure 6. The simulation demonstrates that the pool water temperature decreases during night-time, since the only HP is not enough to guarantee the required temperature in the pool, fixed at $29^{\circ} \mathrm{C}$. Therefore, an integration from the primary circuit powered by the boilers and the cogenerator became necessary. Accordingly, the time for switching on the pool's circulation pump has been anticipated, from 8:00 am to 4:00 am. This auxiliary heat accelerates the water heating process, so when the structure opens, i.e. at 8:00 $\mathrm{am}$, the water temperature has already reached an acceptable value. It is possible to observe that in these moments the water temperature is around $28.5^{\circ} \mathrm{C}$, and at 10:00 am the temperature reaches its full capacity. This is completely acceptable since in the implementation phase, in order to simplify the model, the three different pools were implemented as a single pool with average characteristics. Consequently, the larger the water mass, the greater its thermal inertia, requiring a longer time to raise the temperature. The trend of the evaporated water is in sync with the pool water temperature; when the temperature increases, the amount of water lost through evaporation increases, and when the temperature decreases, so does the evaporated water. On average, the mass of evaporated water is $262.6 \mathrm{~kg} / \mathrm{h}$.

\subsubsection{Economic analysis}

In light of the previous results, it is clear that the two proposed energy-saving actions could be really advantageous for reducing the thermal energy consumption. In order to be able to quantify the advantage obtained with these solutions, it is necessary to compare the results of the simulations of the two innovative plant configurations with the initial virtual model. The gaps between the two models and the initial virtual model represent the achievable energy savings.

The winter simulation carried out with the virtual pool system indicates that the system has a daily average consumption of $8.1 \mathrm{MWht} / \mathrm{day}$. Comparing this value with the average value obtained from the simulation that reproduces the behaviour of the pool in case the first energy efficiency solution is adopted, the average daily consumption is equal to 6.4 MWht/day. This means a gap of $21.2 \%$. In economic terms, a monthly saving of around $€ 1500$ is achieved. With the adoption of the second kind of intervention, the simulation shows that the plant consumes on average 7.6 MWht/day of thermal energy. From the comparison between this model and the virtual model of the pool system, it can be observed that a saving of $5.7 \%$ would be obtained. In economic terms a monthly saving of around $€ 425$ is achieved.

\section{CONCLUSIONS}

The study shows in detail the advantages of adopting a new pool organisation and plant solutions. The results of the analysis demonstrate that the use of the thermal swimming pool covers reduces heat loss, thereby reducing total heat needs. Similarly, the continuous operation of HP coupled with 
new exchangers allows to recover the heat content of the expelled water, reducing total heat requirements from nonrenewable sources. The amount of natural gas cost is reduced when applying alternative concepts.

The work carried out demonstrates that the system serving the swimming pool studied still has large margins of energy optimization even though it is relatively high performance, since it was redesigned after a renovation of the building dating back to 2013. One of the main results of this application is represented by the model calibration based on experimental data. Although these data are affected by relevant uncertainty due to the lack of knowledge of some parameters and to anomalies found during the data acquisition, it is representative of the real case, guaranteeing the respect of thermo-hygrometric requirements and, therefore, of the comfort conditions.

In addition, it is worth noting that, by using a modelling approach, it is possible to evaluate several energy saving solutions. This kind of approach permits to carry out replicable analyses, adapting the numerical system to different swimming centres configuration, investigating their efficiencies and finding solutions for energy saving actions.

\section{ACKNOWLEDGMENT}

Authors thank the Ferrara swimming pool centre management and the Engineers Massimo Savini and Claudia Pacchiega for their support in carrying out the research.

\section{REFERENCES}

[1] Li, Y., Huang, G., Xu, T., Liu, X., Wu, H. (2018). Optimal design of PCM thermal storage tank and its application for winter available open-air swimming pool. Applied Energy, 209: 224-235. https://doi.org/10.1016/j.apenergy.2017.10.095

[2] Lugo, S., Morales, L.I., Best, R., Gómez, V.H., GarcíaValladares, O. (2019). Numerical simulation and experimental validation of an outdoor-swimming-pool solar heating system in warm climates. Solar Energy, 189: 45-56. https://doi.org/10.1016/j.solener.2019.07.041

[3] Calise, F., Capuano, D., Vanoli, L. (2015). Dynamic simulation and exergo-economic optimization of a hybrid solar-geothermal cogeneration plant. Energies, 8(4): 2606-2646. https://doi.org/10.3390/en8042606

[4] Kalogirou, S.A., Tripanagnostopoulos, Y. (2006). Hybrid PV/T solar systems for domestic hot water and electricity production. Energy Conversion and Management, $\quad 47(18-19)$ : 3368-3382. https://doi.org/10.1016/j.enconman.2006.01.012

[5] Jordaan, M., Narayanan, R. (2019). A numerical study on various heating options applied to swimming pool for energy saving. Energy Procedia, 160: 131-138. https://doi.org/10.1016/j.egypro.2019.02.128

[6] Marín, J.D., García, F.V., Cascales, J.G. (2019). Use of a predictive control to improve the energy efficiency in indoor swimming pools using solar thermal energy. Solar Energy, $\quad$ 179: 380-390. https://doi.org/10.1016/j.solener.2019.01.004

[7] Artuso, P., Santiangeli, A. (2008). Energy solutions for sports facilities. International Journal of Hydrogen
Energy,

33(12):

3182-3187.

https://doi.org/10.1016/j.ijhydene.2007.12.064

[8] Kalogirou, S.A. (2004). Solar thermal collectors and applications. Progress in Energy and Combustion Science, 30(3): 231-295.

https://doi.org/10.1016/j.pecs.2004.02.001

[9] Saidur, R., Abdelaziz, E.A., Demirbas, A., Hossain, M. S., Mekhilef, S. (2011). A review on biomass as a fuel for boilers. Renewable and Sustainable Energy Reviews, 15(5): 2262-2289. https://doi.org/10.1016/j.rser.2011.02.015

[10] Lund, J.W. (2010). Direct utilization of geothermal energy. $\quad$ Energies, 3(8): 1443-1471. https://doi.org/10.1016/j.geothermics.2015.11.004

[11] Buonomano, A., De Luca, G., Figaj, R.D., Vanoli, L. (2015). Dynamic simulation and thermo-economic analysis of a PhotoVoltaic/Thermal collector heating system for an indoor-outdoor swimming pool. Energy Conversion and Management, 99: 176-192. https://doi.org/10.1016/j.enconman.2015.04.022

[12] Chow, T.T., Bai, Y., Fong, K.F., Lin, Z. (2012). Analysis of a solar assisted heat pump system for indoor swimming pool water and space heating. Applied Energy, 100:

309-317. https://doi.org/10.1016/j.apenergy.2012.05.058

[13] Katsaprakakis, D.A. (2015). Comparison of swimming pools alternative passive and active heating systems based on renewable energy sources in Southern Europe. Energy, 81: 738-753. https://doi.org/10.1016/j.energy.2015.01.019

[14] Valsuani, F., Tagliafico, G., Tagliafico, L.A. (2011). Energy saving performance of a solar assisted heat pump for swimming pool water heating. The 23rd IIR International Congress of Refrigeration, p. 568. http://localhost/var/www/apps/conversion/tmp/scratch 10/dx.doi.org/10.1016/j.enbuild.2012.10.009

[15] Sun, P., Wu, J.Y., Wang, R.Z., Xu, Y.X. (2011). Analysis of indoor environmental conditions and heat pump energy supply systems in indoor swimming pools. Energy and Buildings, 43(5): 1071-1080. https://doi.org/10.1016/j.enbuild.2010.08.004

[16] Calise, F., Figaj, R.D., Vanoli, L. (2018). Energy and economic analysis of energy savings measures in a swimming pool centre by means of dynamic simulations. Energies, $11(9)$ : https://doi.org/10.3390/en11092182

[17] "Solar Heating Systems for Swimming Pools." Australian Standard AS3634-1989, Standards Australia.

[18] Dongellini, M., Falcioni, S., Martelli, A., Morini, G.L. (2015). Dynamic simulation of outdoor swimming pool solar heating. Energy Procedia, 81: 1-10. https://doi.org/10.1016/j.egypro.2015.12.053

[19] Asdrubali, F. (2009). A scale model to evaluate water evaporation from indoor swimming pools. Energy and Buildings, 41(3): 311-319. https://doi.org/10.1016/j.enbuild.2008.10.001

[20] Smith, C.C., Löf, G., Jones, R. (1994). Measurement and analysis of evaporation from an inactive outdoor swimming pool. Solar Energy, 53(1): 3-7. https://doi.org/10.1016/S0038-092X(94)90597-5

[21] Lam, J.C., Chan, W.W. (2001). Life cycle energy cost analysis of heat pump application for hotel swimming pools. Energy Conversion and Management, 42(11): 
1299-1306.

8904(00)00146-1

https://doi.org/10.1016/S0196-

[22] Ruiz, E., Martínez, P.J. (2010). Analysis of an open-air swimming pool solar heating system by using an experimentally validated TRNSYS model. Solar Energy, $84(1)$ 116-123.

https://doi.org/10.1016/j.solener.2009.10.015

[23] TRNSYS manual.

[24] VDI 2089 Wärme-, Raumlufttechnik, Wasserver- und entsorgung in Hallen- und Freibäder Hallenbäder Juli, 1994.

[25] Czarnecki, J.T. (1978). Swimming pool heating by solar energy CSIRO division of mechanical engineering technical report TR 19.

[26] Zuccari, F., Santiangeli, A., Orecchini, F. (2017). Energy analysis of swimming pools for sports activities: cost effective solutions for efficiency improvement. Energy Procedia, 126: $123-130$.

https://doi.org/10.1016/j.egypro.2017.08.131

\section{NOMENCLATURE}

A surface Area, $\mathrm{m}^{2}$

F activity factor, dimensionless

Q rate of heat transfer, $\mathrm{kJ}$

$\mathrm{T}$ absolute temperature, ${ }^{\circ} \mathrm{C}$

$\mathrm{V} \quad$ volume, $\mathrm{m}^{3}$

W evaporation rate, $\mathrm{kg} . \mathrm{h}^{-1}$

c specific heat, $\mathrm{kJ} \cdot \mathrm{kg}^{-1} \cdot \mathrm{K}^{-1}$

h enthalpy, kJ

$\mathrm{h}^{*} \quad$ heat transfer coefficient, $\mathrm{W} \cdot \mathrm{m}^{-2} \cdot \mathrm{K}^{-1}$

m mass, $\mathrm{kg}$

m mass flow rate, $\mathrm{kg} \cdot \mathrm{s}^{-1}$

$\mathrm{p}$ pressure, $\mathrm{Pa}$

$\mathrm{t}$ time lapse, $\mathrm{h}$
W

total evaporation coefficient, dimensionless

\section{Greek symbols}

$\varepsilon \quad$ emissivity

$\varphi \quad$ relative humidity of the air, $\%$

$\lambda \quad$ thermal conductivity, $\mathrm{W} \cdot \mathrm{m}^{-1} \mathrm{~K}^{-1}$

$\rho$ density, $\mathrm{kg} / \mathrm{m}^{-3}$

$\sigma \quad$ Stefan-Boltzmann constant: $5.67 \times 10^{-8} \mathrm{~W} . \mathrm{m}^{-2} . \mathrm{K}$ 4

$\theta \quad$ temperature, ${ }^{\circ} \mathrm{C}$

\section{Subscripts}

$\begin{array}{ll}\text { a } & \text { air } \\ \text { amb } & \text { ambient } \\ p & \text { pool } \\ \text { st } & \text { steam } \\ \text { sat } & \text { saturation } \\ \text { tot } & \text { total } \\ w & \text { water } \\ \text { wall } & \text { walls of the room } \\ \text { evap } & \text { due to evaporation } \\ \text { rad } & \text { due to radiation heat transfer } \\ \text { cond } & \text { due to conduction heat transfer } \\ \text { conv } & \text { due to convection heat transfer } \\ \text { refill } & \text { due to water renovation process } \\ \text { in } & \text { due to extra heating }\end{array}$

\section{Acronyms}

$\begin{array}{ll}\text { AHU } & \text { Air Handler Unit } \\ \text { DHW } & \text { Domestic Hot Water } \\ \text { HP } & \text { Heat pump } \\ \text { TRNSYS } & \text { Transient System Simulation Tool }\end{array}$ 